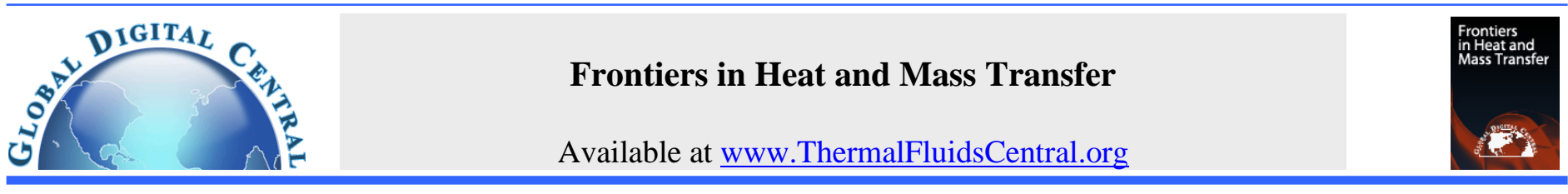

\title{
NUMERICAL ANALYSES ON VAPOR PRESSURE DROP IN A CENTERED-WICK ULTRA-THIN HEAT PIPE
}

\author{
Yasushi Koito ${ }^{\mathrm{a}, *}$ \\ ${ }^{a}$ Kumamoto University, Kumamoto-shi, Kumamoto, 860-8555, Japan
}

\begin{abstract}
This paper describes extended numerical analyses on vapor pressure distribution in a centered-wick ultra-thin heat pipe. Analyses were conducted by using a three-dimensional model developed by the author. Numerical results were obtained changing design parameters and operating conditions of the heat pipe. Discussion was made on the heat transfer limit as well as the vapor pressure drop. Moreover, a simple method was also presented to evaluate the vapor pressure drop in the ultra-thin heat pipe. Calculated results with the simple method agreed in $10 \%$ with the three-dimensional numerical results.
\end{abstract}

Keywords: Heat pipe, Ultra-thin electronic device, Thermal management, Vapor pressure drop, Simple evaluation

\section{INTRODUCTION}

In recent years, among many studies on heat pipes (e.g., Mirmanto et al., 2018; Petrucci and Faghri, 2018; Orr et al., 2019; Taft and Irick, 2019), attempts have been made to develop an ultra-thin heat pipe, which has been used especially for the enhancement of cooling of smartphones. Removal of heat is required for smartphones with the increase in performance. Same as conventional heat pipes of normal size, the ultrathin heat pipe also transports heat passively from a heated to cooled sections utilizing latent heat of a working fluid. Evaporation and condensation take place in the heat pipe. However, compared to the conventional heat pipes, a thickness of the ultra-thin heat pipe is very small; the heat pipes with the thickness of less than $1 \mathrm{~mm}$ were already developed.

Ahamed et al. (2015) introduced a centered wick structure named as "Center Fiber Wick" and fabricated an ultra-thin flattened heat pipe. The structure of the heat pipe was made by flattening a copper tube, and the size of the flattened heat pipe was $100 \mathrm{~mm}$ (length) $\times 3 \mathrm{~mm}$ (width) $\times 0.4 \mathrm{~mm}$ (thickness). Ahamed et al. (2017) disclosed extended experimental results on the thermal performance of the ultra-thin flattened heat pipe. In this experiment, a length, a width and a thickness of the heat pipe were changed as $50 \mathrm{~mm}-120 \mathrm{~mm}, 3.0 \mathrm{~mm}-7.8 \mathrm{~mm}$ and $0.35 \mathrm{~mm}-0.60 \mathrm{~mm}$, respectively. Recent studies concerning the ultra-thin flattened heat pipes were already reviewed in the author's previous paper (Koito, 2019). In addition, Tang et al. (2017) fabricated a novel sintered copper mesh wick and Zhou et al. (2019) developed a novel bi-porous spiral woven mesh wick in order to enhance the thermal performance of the ultra-thin flattened heat pipes. A structure of the ultrathin heat pipe is not limited to the above-mentioned flattened type; a flatplate type, which is also referred to as "Vapor Chamber", and a loop type have been also developed in recent years. Zhang et al. (2019) and Chen et al. (2019) developed the ultra-thin flat-plate heat pipes; their dimensions were $26 \mathrm{~mm} \times 200 \mathrm{~mm} \times 1.5 \mathrm{~mm}$ (thickness) and $120 \mathrm{~mm} \times$ $120 \mathrm{~mm} \times 2.0 \mathrm{~mm}$ (thickness), respectively. Ultra-thin loop heat pipes, on the other hand, were fabricated by Zhou et al. (2016) and Hong et al.
(2017). Same as conventional loop heat pipes, these ultra-thin loop heat pipes were also composed of an evaporator and condenser sections with a vapor and liquid lines connecting them. Zhou et al. (2016) employed a $1.2 \mathrm{~mm}$ thick flat evaporator and a vapor line, liquid line and condenser with a $1.0 \mathrm{~mm}$ thickness. The loop heat pipe made by Hong et al. (2017) was $1.5 \mathrm{~mm}$ in thickness.

A vapor flow space in the ultra-thin heat pipe is very small, and therefore a vapor pressure drop due to viscous friction would be large compared to that in a conventional heat pipe of normal size. Since the vapor pressure drop would influence the heat pipe performance, the discussion concerning the vapor pressure drop is indispensable for further development of ultra-thin heat pipes. In the previous study (Koito, 2019), therefore, the author developed a three-dimensional mathematical model to clarify the velocity, pressure and temperature distributions in the ultra-thin heat pipe. By using the experimental results by Zhou et al. (2017), the confirmation was obtained on the validity of the mathematical model.

This paper describes extended numerical analyses on the vapor pressure drop in the ultra-thin heat pipe. A wick structure was positioned at center of a vapor flow space. The above-mentioned author's threedimensional mathematical model was used, and numerical results were obtained by changing design parameters and operating conditions. Discussion was made on the heat transfer limit as well as the vapor pressure drop. A simple method was also presented to evaluate the vapor pressure drop in the heat pipe.

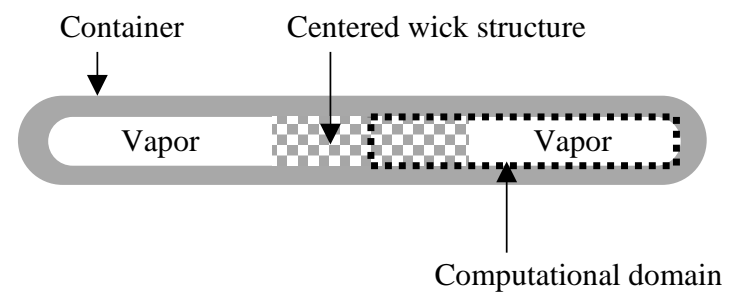

Fig. 1 Computational domain (Koito, 2019). 


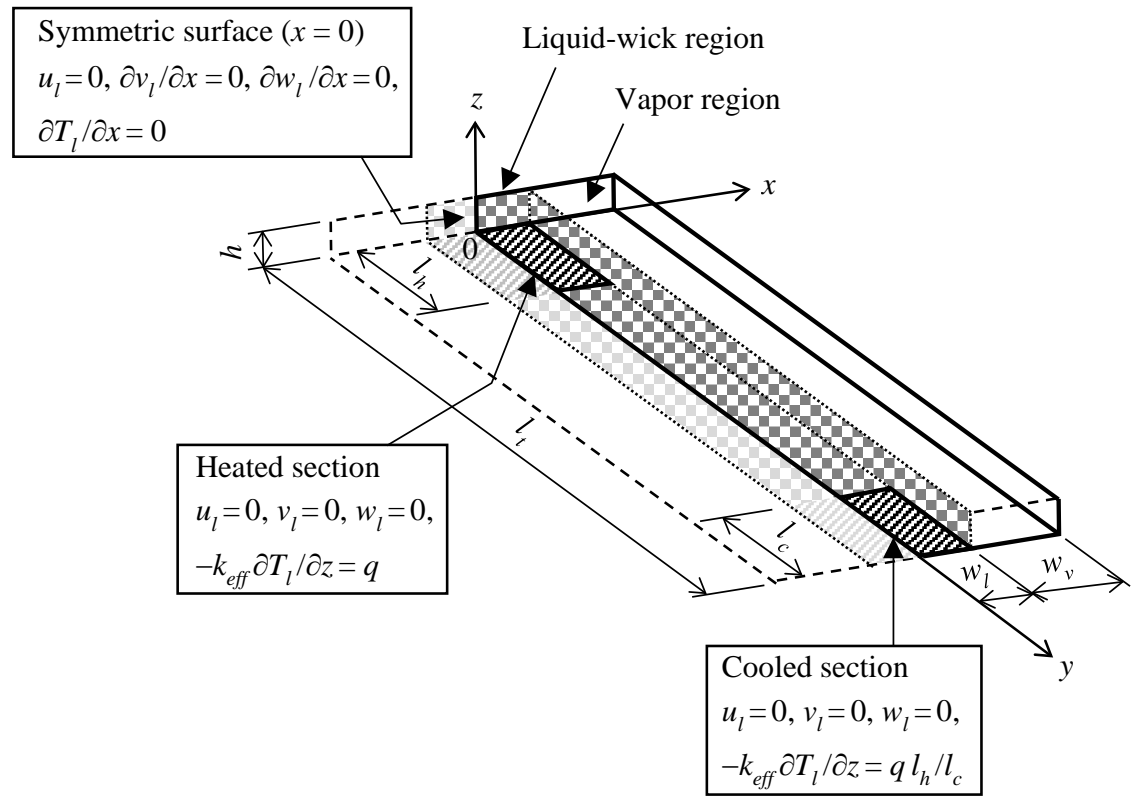

Fig. 2 Mathematical model.

\section{MATHEMATICAL MODEL AND NUMERICAL CONDITIONS}

Details of mathematical modeling were already described in the author' previous paper (Koito, 2019). Therefore, its brief summary is described below.

A cross section of the ultra-thin heat pipe with a centered wick structure is shown in Fig. 1. A computational domain was indicated with dotted lines in this figure. Because the cross section was symmetrical, a half domain of the heat pipe was analyzed. As shown in Fig. 2, the mathematical model (length: $l$, width: $w_{l}+w_{v}$, height: $h$ ) consisted of two regions of a vapor and a liquid-wick. The widths of the vapor and liquidwick regions were $w_{v}$ and $w_{l}$, respectively while the length and the height were both $l_{t}$ and $h$, respectively. One end (length: $l_{h}$, width: $\left.w_{l}\right)$ of the bottom surface was heated while the other end (length: $l_{c}$, width: $w_{l}$ ) cooled. The following equations were solved numerically to obtain the distributions of the velocities, $u, v, w$, in $x, y, z$ directions, the pressure, $p$, and the temperature, $T$, in the vapor and liquid-wick regions.

For the vapor region:

$\nabla \cdot \boldsymbol{V}_{v}=0$

$\rho_{v} \boldsymbol{V}_{v} \cdot \nabla \boldsymbol{V}_{v}=-\nabla p_{v}+\mu_{v} \nabla^{2} \boldsymbol{V}_{v}$

$\rho_{v} c_{p, v} \boldsymbol{V}_{v} \cdot \nabla T_{v}=k_{v} \nabla^{2} T_{v}$

For the liquid-wick region:

$\nabla \cdot V_{l}=0$

$\rho_{l} \boldsymbol{V}_{\boldsymbol{l}} \cdot \nabla \boldsymbol{V}_{\boldsymbol{l}}=-\nabla p_{l}+\mu_{l} \nabla^{2} \boldsymbol{V}_{\boldsymbol{l}}-\frac{\varepsilon \mu_{l} \boldsymbol{V}_{\boldsymbol{l}}}{K}$

$\rho_{l} c_{p, l} \boldsymbol{V}_{l} \cdot \nabla T_{l}=\frac{k_{e f f}}{\varepsilon} \nabla^{2} T_{l}$ where $\rho$ is the density, $\mu$ the viscosity, $c_{p}$ the specific heat at constant pressure, $k$ the thermal conductivity. $\boldsymbol{V}$ is the velocity vector $(=(u, v, w))$. Darcy's law was employed in Eq. (5) using the porosity, $\varepsilon$, and the permeability, $K$. The effective thermal conductivity, $k_{\text {eff, }}$ was employed in Eq. (6). Subscripts of $v$ and $l$ mean the vapor and liquid-wick regions, respectively.

At the interface between the vapor and liquid-wick regions, the temperature was considered to be a saturated temperature, $T_{\text {sat }}$, and the boundary conditions were expressed as follows:

$$
\begin{aligned}
& u_{v}=\frac{-k_{e f f}\left(\frac{\partial T_{l}}{\partial x}\right)}{\rho_{v} h_{f g}}, \quad u_{l}=\frac{-k_{e f f}\left(\frac{\partial T_{l}}{\partial x}\right)}{\rho_{l} h_{f g}}, \\
& v_{v}=v_{l}=0, \quad w_{v}=w_{l}=0, \\
& T_{v}=T_{l}=T_{\text {sat }}=\left(\frac{1}{T_{\text {ref }}}-\frac{R_{g}}{h_{f g}} \ln \frac{p_{v}}{p_{\text {ref }}}\right)^{-1}
\end{aligned}
$$

where $h_{f g}$ is the latent heat. The Clausius-Clapeyron equation was employed using the reference temperature, $T_{r e f}$, the reference pressure, $p_{\text {ref, }}$ and the gas constant, $R_{g}$. The boundary conditions at the symmetric surface $(x=0)$ as well as the heated and cooled sections are shown in Fig. 2, where $q$ is the given heat flux. Except for the heated and cooled sections, an adiabatic condition was applied on the outer surface of the model. In addition, because only temperature gradients were given on the outer surface, the temperature at $x=w l, y=l_{t} / 2, z=h / 2$ was also prescribed as an operating temperature. This operating temperature was denoted by $T_{o}$.

Numerical conditions are shown in Table 1 , where the values of $l_{c}$, $h, q$ and $T_{o}$ were changed. In addition, sintered copper powder and water were selected as a wick structure and a working fluid, respectively. The value of $k_{\text {eff }}$ was evaluated using Yagi-Kunii's equation (JAHP, 2001). $\varepsilon$ $=0.4$ and $K=9.00 \times 10^{-13} \mathrm{~m}^{2}$ were given in the present numerical analyses. The value of porosity was obtained from a wick supplier. The value of permeability was cited from Faghri (2016). 
Table 1 Numerical conditions.

\begin{tabular}{|l|l|}
\hline Length of vapor/liquid-wick regions, $l_{t}[\mathrm{~mm}]$ & 100 \\
\hline Length of heated section, $l_{h}[\mathrm{~mm}]$ & 10 \\
\hline Length of cooled section, $l_{c}[\mathrm{~mm}]$ & $10,30,60,90$ \\
\hline Width of liquid-wick region, $w_{l}[\mathrm{~mm}]$ & 0.5 \\
\hline Width of vapor region, $w_{v}[\mathrm{~mm}]$ & 1.0 \\
\hline Height of vapor/liquid-wick regions, $h[\mathrm{~mm}]$ & $0.2,0.3,0.4,0.5$ \\
\hline Heat flux at heated section, $q\left[\mathrm{~W} / \mathrm{cm}^{2}\right]$ & $\begin{array}{l}0,10,20,30, \cdots \\
\text { (below viscous limit) }\end{array}$ \\
\hline Operating temperature, $T_{o}\left[{ }^{\circ} \mathrm{C}\right]$ & 40,50 \\
\hline
\end{tabular}

\section{RESULTS AND DISCUSSION}

\subsection{Results of Three-dimensional Numerical Analyses}

The vapor pressure distributions in $y$ direction at $h=0.2 \mathrm{~mm}, 0.3 \mathrm{~mm}$, $0.4 \mathrm{~mm}$ and $0.5 \mathrm{~mm}$ are shown in Fig. 3 when $l_{c}=10 \mathrm{~mm}, q=20 \mathrm{~W} / \mathrm{cm}^{2}$ and $T_{o}=50^{\circ} \mathrm{C}$. The numerical results of $p_{v}$ at $z=h / 2$ on the vapor-liquid interface are shown in this figure. Under the same heat inputs, as mentioned in the author's previous paper (Koito, 2019), the vapor velocity becomes higher as the cross section $\left(=w_{v} \times h\right)$ of the vapor flow space decreases. Therefore, the vapor pressure difference over the vapor region became larger as $h$ decreased. It was found that the vapor pressure difference over the vapor region was comparatively large at $h=0.2 \mathrm{~mm}$. The difference between the vapor pressure distributions at $h=0.4 \mathrm{~mm}$ and $h=0.5 \mathrm{~mm}$ was very small; however, relatively large difference was found between $h=0.2 \mathrm{~mm}$ and $h=0.3 \mathrm{~mm}$. Although the difference in $h$ was only $0.1 \mathrm{~mm}$, the vapor pressure drop at $h=0.2 \mathrm{~mm}$ was considerably larger than that at $h=0.3 \mathrm{~mm}$. Since the vapor region was in a saturated condition, the vapor temperature drop also became larger with the vapor pressure drop causing to increase the thermal resistance of the heat pipe.

The vapor velocity distributions are shown in Fig. 4 when $h=0.2$ $\mathrm{mm}, q=20 \mathrm{~W} / \mathrm{cm}^{2}$ and $T_{o}=50{ }^{\circ} \mathrm{C}$. The two cases of (a) $l_{c}=10 \mathrm{~mm}$ and (b) $l_{c}=60 \mathrm{~mm}$ are compared in this figure. The vapor flows from the vapor-liquid interface at the heated section to that at the cooled section were shown in these figures; however, the vapor velocity at the cooled section for (b) $l_{c}=60 \mathrm{~mm}$ was found to be smaller than that for (a) $l_{c}=$ $10 \mathrm{~mm}$ implying that the vapor velocity was decreased with the increase in $l_{c}$. As shown in Fig. 2, the heat flux at the cooled section was given and the value was calculated as $q\left(l_{h} / l_{c}\right)$. Therefore, although the cooling surface area was increased, the value of $q\left(l_{h} / l_{c}\right)$ became smaller with the increase in $l_{c}$ causing the decrease in the vapor velocity over the cooled section. The vapor pressure distributions in $y$ direction at $l_{c}=10 \mathrm{~mm}, 30$ $\mathrm{mm}, 60 \mathrm{~mm}$ and $90 \mathrm{~mm}$ are shown in Fig. 5 when $h=0.2 \mathrm{~mm}, q=20$ $\mathrm{W} / \mathrm{cm}^{2}$ and $T_{o}=50{ }^{\circ} \mathrm{C}$. Same as Fig. 3, the numerical results of $p_{v}$ at $z=$ $h / 2$ on the vapor-liquid interface are shown in this figure. It was found that the vapor pressure difference over the vapor region became smaller as $l_{c}$ increased confirming that the cooled surface area was one of the factors affecting the vapor pressure drop in the heat pipe with the ultrathin structure.

From each numerical result, the minimum values of the vapor pressure, $p_{v, \min }$, were obtained and the heat transfer rate of the heat pipe, $Q$, was calculated by the following equation:

$$
Q=2 q w_{l} l_{h}
$$

Since the computational domain was a half of an actual centered-wick heat pipe (see Fig. 1), the value of $Q$ was obtained by multiplying the heat input to the heated section $\left(=q w_{l} l_{h}\right)$ by 2 . The relations between $p_{v, \min }$ and $Q$ are shown in Fig. 6 for the three cases of (1) $h=0.2 \mathrm{~mm}, T_{o}$ $=50{ }^{\circ} \mathrm{C}$, (2) $h=0.4 \mathrm{~mm}, T_{o}=50^{\circ} \mathrm{C}$ and (3) $h=0.2 \mathrm{~mm}, T_{o}=40^{\circ} \mathrm{C}$ when $l_{c}=10 \mathrm{~mm}$ and $q=20 \mathrm{~W} / \mathrm{cm}^{2}$. In all cases, $p_{v, \min }$ deceased with the

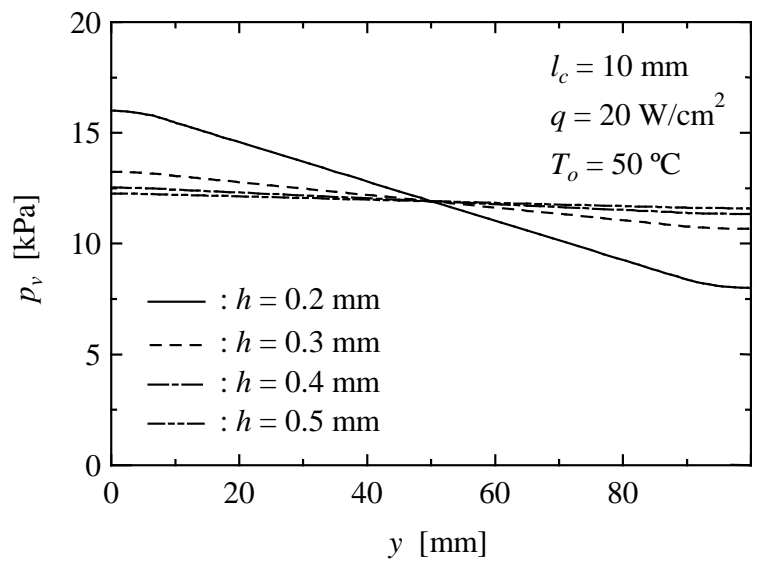

Fig. 3 Vapor pressure distributions; effect of the vapor region height.

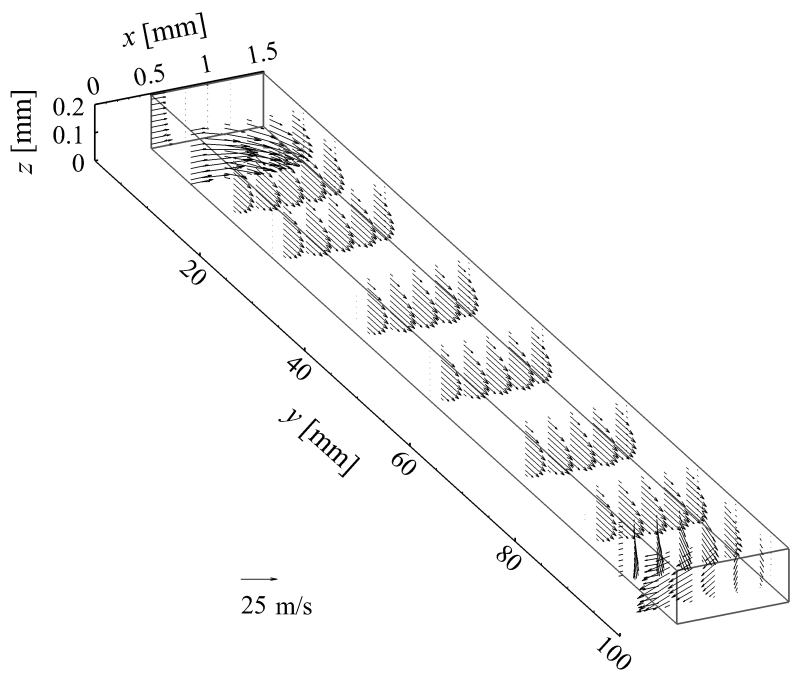

(a) $l_{c}=10 \mathrm{~mm}$

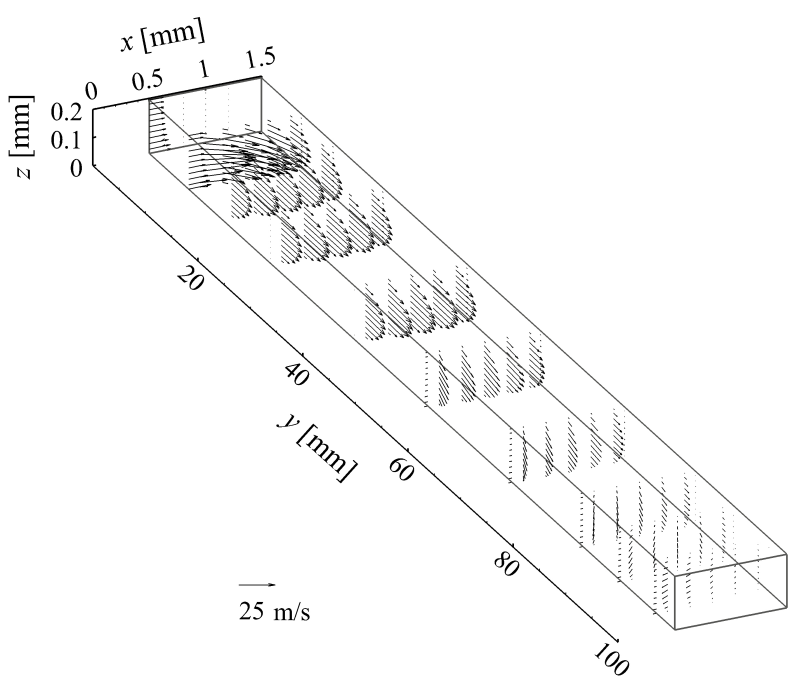

(b) $l_{c}=60 \mathrm{~mm}$

Fig. 4 Vapor velocity distributions $\left(h=0.2 \mathrm{~mm}, q=20 \mathrm{~W} / \mathrm{cm}^{2}\right.$, $\left.T_{o}=50^{\circ} \mathrm{C}\right)$. 
increase in $Q$ because of the increase in the vapor velocity. From the comparison between (1) and (2), it was found that the decrease in $p_{v, \text { min }}$ with the increase in $Q$ for $h=0.2 \mathrm{~mm}$ was more significant than that for $h=0.4 \mathrm{~mm}$. This was due to a smaller cross section of the vapor region. According to a heat pipe theory (Faghri, 2016), a heat pipe encounters heat transfer limitation when $p_{v, \min }=0$. This heat transfer limitation is categorized as a viscous limit. The value of $Q$ when $p_{v, \min }=0$, which implies the maximum heat transfer rate, $Q_{\max }$, was evaluated for the two cases of (1) and (3) by extrapolating the numerical results of $p_{v, \min }$ as shown in the figure by dashed lines. The values of $Q_{\max }$ are also shown in the figure. The difference in $T_{o}$ between the two cases of (1) and (3) was $10{ }^{\circ} \mathrm{C}$; nevertheless, the value of $Q_{\max }$ for $T_{o}=40{ }^{\circ} \mathrm{C}$ was found to be much smaller than that for $T_{o}=50^{\circ} \mathrm{C}$. Therefore, regarding the ultrathin heat pipe, it was confirmed that the viscous limit was a possible limitation and the maximum heat transfer rate was greatly affected by the operating temperature of the heat pipe.

\subsection{Simple Evaluation of Vapor Pressure Drop}

An attempt was also made to present a simple method to evaluate the vapor pressure drop. In this calculation, a one-dimensional vapor flow in $y$ direction between two parallel walls was considered. These walls were positioned with a gap of $h$. A $z$ axis was also given perpendicular to the walls. Under this condition, Eq. (2) was simplified as follows:

$\mu_{v} \frac{d^{2} v_{v}}{d z^{2}}=\frac{d p_{v}}{d y}$

The integration of Eq. (9) with $v_{v}=0$ both at $z=0$ and $z=h$ yielded the following equation:

$$
v_{v}=-\frac{1}{2 \mu_{v}} \frac{d p_{v}}{d y}(h-z) z
$$

The vapor volume flow rate, $V_{v}$, was calculated by

$$
V_{v}=w_{v} \int_{0}^{h} v_{v} d z
$$

and the substitution of Eq. (10) into Eq. (11) yielded the following equation:

$$
\frac{d p_{v}}{d y}=-\frac{12 \mu_{v} V_{v}}{w_{v} h^{3}}
$$

From a mass balance, on the other hand, a change in the vapor volume flow rate in $y$ direction, $d V_{v} / d y$, was given as follows for the heated, adiabatic and cooled sections, respectively.

$$
\frac{d V_{v}}{d y}=\left\{\begin{array}{cl}
\frac{q w_{l}}{\rho_{v} h_{f g}} & \text { for the heated section } \\
0 & \text { for the adiabatic section } \\
-\frac{q\left(l_{h} / l_{c}\right) w_{l}}{\rho_{v} h_{f g}} & \text { for the cooled section }
\end{array}\right.
$$

The vapor pressure distributions over the vapor region were obtained simply with Eqs. (12) and (13). The calculated results with Eqs. (12) and (13) were compared with the results of three-dimensional numerical analyses. The comparisons were shown in Figs. 7 and 8 concerning the vapor pressure distribution, $p_{v}$, and the total vapor pressure difference, $\Delta p$, respectively. $\Delta p$ was evaluated by the following equation:

$$
\Delta p=p_{i, h}-p_{i, c}
$$

where $p_{i, h}$ and $p_{i, c}$ are the vapor pressures on the vapor-liquid interface at the ends of heated side $(y=0, z=h / 2)$ and cooled side $\left(y=l_{t}, z=h / 2\right)$, respectively. In Fig. 7, the comparison of $p_{v}$ was made for the two cases

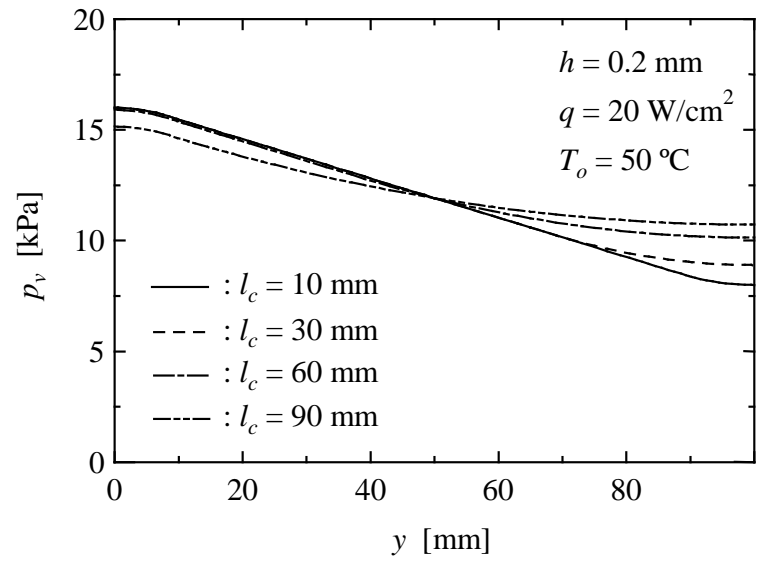

Fig. 5 Vapor pressure distributions; effect of the cooled section length.

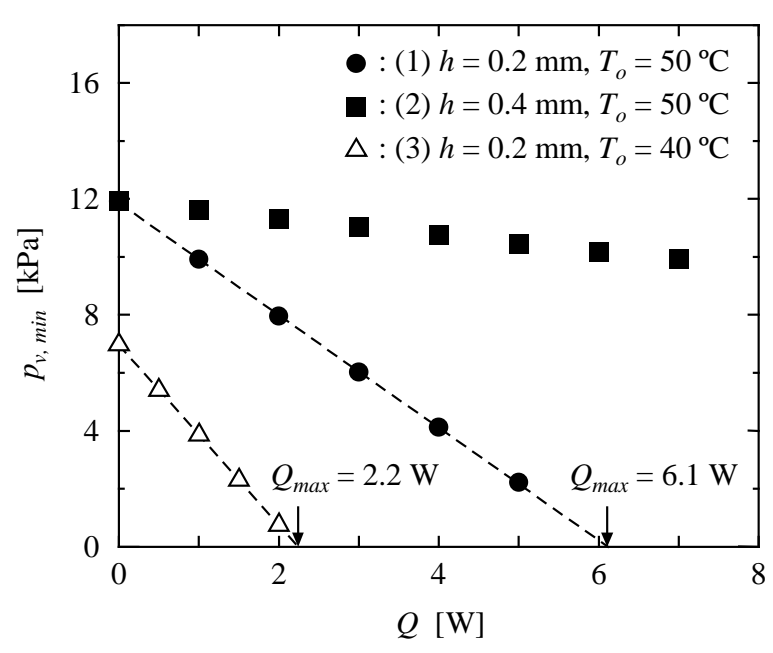

Fig. 6 Relations between the minimum vapor pressure and the heat transfer rate $\left(l_{c}=10 \mathrm{~mm}, q=20 \mathrm{~W} / \mathrm{cm}^{2}\right)$.

of $h=0.2 \mathrm{~mm}$ and $h=0.4 \mathrm{~mm}$ when $l_{c}=10 \mathrm{~mm}, q=20 \mathrm{~W} / \mathrm{cm}^{2}$ and $T_{o}=$ $50{ }^{\circ} \mathrm{C}$. Fig. 8 was obtained changing $q$ and $l_{c}$ as shown in the figure. Because the effect of friction at the walls of $x=w_{l}$ and $x=w_{l}+w_{v}$ in Fig. 2 was not considered in the simple calculations, the vapor pressure distributions in Fig. 7 and the total pressure differences in Fig. 8 calculated with Eqs. (12) and (13) were found to be slightly smaller than those of the three-dimensional numerical analyses. In a range of the present calculations, the difference between the simple calculations and the numerical results was found to be $10 \%$ confirming the validity of the simple calculations.

\section{CONCLUSIONS}

Extended numerical analyses were conducted concerning the vapor pressure drop and the viscous limit of the centered-wick ultra-thin heat pipe. The numerical results were obtained using the three-dimensional mathematical model developed by the author. Regarding the ultra-thin heat pipe, the findings were summarized as follows under the present numerical conditions and the calculation range.

- The vapor pressure drop with the vapor flow space of $0.2 \mathrm{~mm}$ in height was much larger than that of $0.3 \mathrm{~mm}$ although their difference in height was only $0.1 \mathrm{~mm}$. 
- $\quad$ The cooled surface area was also one of the factors affecting the vapor pressure drop.

- The viscous limit was a possible limitation and the maximum heat transfer rate was greatly affected by the operating temperature.

- The present simple method was effective to evaluate the vapor pressure drop.

\section{NOMENCLATURE}

$\begin{array}{ll}c_{p} & \text { specific heat at constant pressure }(\mathrm{J} /(\mathrm{kg} \cdot \mathrm{K})) \\ h & \text { height }(\mathrm{mm}, \mathrm{m}) \\ h_{f g} & \text { latent heat }(\mathrm{J} / \mathrm{kg}) \\ K & \text { permeability }\left(\mathrm{m}^{2}\right) \\ k & \text { thermal conductivity }(\mathrm{W} /(\mathrm{m} \cdot \mathrm{K})) \\ k_{e f f} & \text { effective thermal conductivity }(\mathrm{W} /(\mathrm{m} \cdot \mathrm{K})) \\ l & \text { length }(\mathrm{mm}, \mathrm{m}) \\ p & \text { pressure }(\mathrm{Pa}, \mathrm{kPa}) \\ p_{\text {ref }} & \text { reference pressure }(\mathrm{Pa}, \mathrm{kPa}) \\ Q & \text { heat transfer rate }(\mathrm{W}) \\ q & \text { heat flux }\left(\mathrm{W} / \mathrm{cm}^{2}, \mathrm{~W} / \mathrm{m}^{2}\right) \\ R_{g} & \text { gas constant }(\mathrm{J} /(\mathrm{kg} \cdot \mathrm{K})) \\ T & \text { temperature }\left({ }^{\circ} \mathrm{C}\right) \\ T_{o} & \text { operating temperature }\left({ }^{\circ} \mathrm{C}\right) \\ T_{r e f} & \text { reference temperature }\left({ }^{\circ} \mathrm{C}\right) \\ T_{\text {sat }} & \text { saturated temperature }\left({ }^{\circ} \mathrm{C}\right) \\ u & \text { velocity in } x \text { direction }(\mathrm{m} / \mathrm{s}) \\ V & \text { velocity vector }(=(u, v, w))(\mathrm{m} / \mathrm{s}) \\ v & \text { velocity in } y \text { direction }(\mathrm{m} / \mathrm{s}) \\ w & \text { width }(\text { mm, m); velocity in } z \text { direction }(\mathrm{m} / \mathrm{s}) \\ x, y, z & \text { three-dimensional coordinate }(\mathrm{mm}, \mathrm{m})\end{array}$

\section{Greek Symbols}

$\begin{array}{ll}\Delta p & \text { total vapor pressure difference }(\mathrm{Pa}, \mathrm{kPa}) \\ \varepsilon & \text { porosity } \\ \mu & \text { viscosity }(\mathrm{Pa} \cdot \mathrm{s}) \\ \rho & \text { density }\left(\mathrm{kg} / \mathrm{m}^{3}\right)\end{array}$

\section{Subscripts}

$\begin{array}{ll}c & \text { cooled } \\ h & \text { heated } \\ i & \text { interface } \\ l & \text { liquid-wick region } \\ \max & \text { maximum } \\ \min & \text { minimum } \\ t & \text { total } \\ v & \text { vapor region }\end{array}$

\section{REFERENCES}

Ahamed, M.S., Saito, Y., Mochizuki, M. and Mashiko, K., 2015, "Hot Spot Elimination by Thin and Smart Heat Spreader," InterPACK/ICNMM2015-48019, Proceedings of the ASME 2015 International Technical Conference and Exhibition on Packaging and Integration of Electronic and Photonic Microsystems, San Francisco, CA.

Ahamed, M.S., Saito, Y., Mashiko, K. and Mochizuki, M., 2017, "Characterization of a High Performance Ultra-thin Heat Pipe Cooling Module for Mobile Hand Held Electronic Devices," Heat and Mass Transfer, 53, 3241-3247. http://dx.doi.org/10.1007/s00231-017-2022-7

Chen, G., Tang, Y., Wan, Z., Zhong, G., Tang, H. and Zeng, J., 2019, "Heat Transfer Characteristic of an Ultra-thin Flat Plate Heat Pipe with Surface Functional Wicks for Cooling Electronics," International Communications in Heat and Mass Transfer, 100, 12-19.

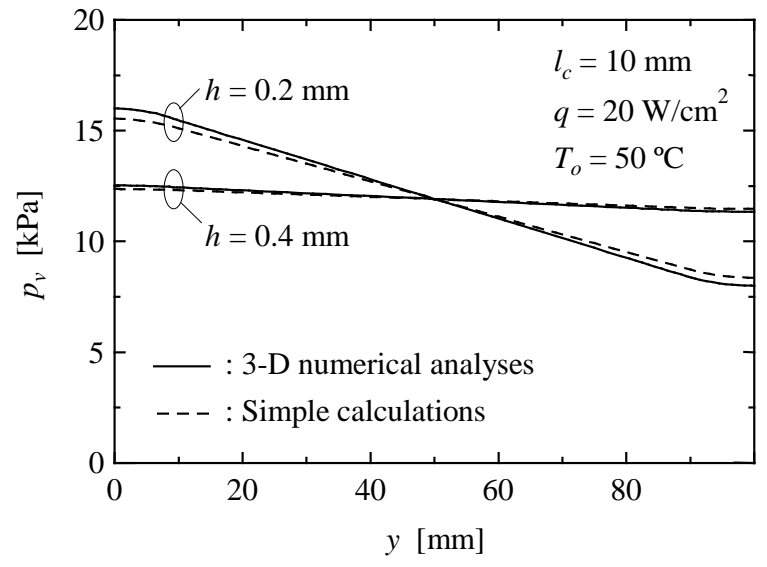

Fig. 7 Comparison between the results of simple calculations and three-dimensional numerical analyses; vapor pressure distributions.

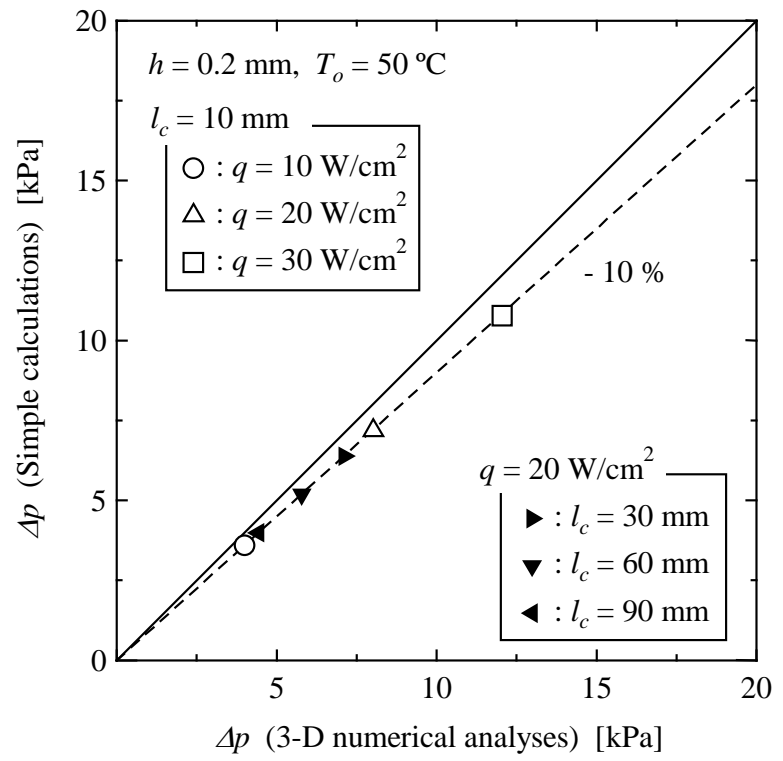

Fig. 8 Comparison between the results of simple calculations and three-dimensional numerical analyses; total pressure differences.

https://doi.org/10.1016/j.icheatmasstransfer.2018.10.011

Faghri, A., 2016, Heat Pipe Science and Technology, $2^{\text {nd }}$ ed., Global Digital Press.

Hong, S., Wang, S. and Zhang, L., 2017, "Effect of Groove Configuration on Two-phase Flow Instability for Ultra-thin Looped Heat Pipes in Thermal Management System,” International Journal of Thermal Sciences, 121, 369-380. http://dx.doi.org/10.1016/j.ijthermalsci.2017.07.024

Japan Association for Heat Pipes (JAHP), 2001, Jitsuyou Heat Pipe, $2^{\text {nd }}$ ed., Nikkan Kogyo Shimbun, Ltd., Tokyo (in Japanese).

Koito, Y., 2019, "Numerical Analyses on Heat Transfer Characteristics of Ultra-thin Heat Pipes: Fundamental Studies with a Three-dimensional Thermal-fluid Model,” Applied Thermal Engineering, 148, 430-437. https://doi.org/10.1016/j.applthermaleng.2018.10.119 
Mirmanto, M., Alit, I.B., Sayoga, I.M.A., Sutanto, R., Nurchayati, N. and Mulyanto, A., 2018, "Experimental Cooler Box Performance Using Two Different Heat Removal Units: A Heat Sink Fin-fan, and a Double Fan Heat Pipe,” Frontiers in Heat and Mass Transfer, 10, 34. https://doi.org/10.5098/hmt.10.34

Orr, B., Singh, R., Akbarzadeh, A. and Mochizuki, M., 2019, “Operating Characteristics of Naphthalene Heat Pipes," Frontiers in Heat and Mass Transfer, 13, 8.

https://doi.org/10.5098/hmt.13.8

Petrucci, M. and Faghri, A., 2018, "Heat Pipe Turbine Vane Integration in Gas Turbine Engines," Frontiers in Heat and Mass Transfer, 11, 37. https://doi.org/10.5098/hmt.11.37

Taft, B.S. and Irick, K.W., 2019, “ASETS-II Oscillating Heat Pipe Space Flight Experiment: The First Six Months on Orbit," Frontiers in Heat and Mass Transfer, 12, 24.

https://doi.org/10.5098/hmt.12.24

Tang, Y., Tang, H., Li, J., Zhang, S., Zhuang, B. and Sun, Y., 2017, "Experimental Investigation of Capillary Force in a Novel Sintered Copper Mesh Wick for Ultra-thin Heat Pipes,” Applied Thermal Engineering, 115, 1020-1030. http://dx.doi.org/10.1016/j.applthermaleng.2016.12.056

Zhang, S., Chen, J., Sun, Y., Li, J., Zeng, J., Yuan, W. and Tang, Y., 2019, "Experimental Study on the Thermal Performance of a Novel Ultra-thin Aluminum Flat Heat Pipe,” Renewable Energy, 135, 11331143.

https://doi.org/10.1016/j.renene.2018.12.097

Zhou, G., Li, J. and Lv, L., 2016, “An Ultra-thin Miniature Loop Heat Pipe Cooler for Mobile Electronics,” Applied Thermal Engineering, 109, 514-523.

http://dx.doi.org/10.1016/j.applthermaleng.2016.08.138

Zhou, W., Xie, P., Li, Y., Yan, Y. and Li, B., 2017, "Thermal Performance of Ultra-thin Flattened Heat Pipes,” Applied Thermal Engineering, 117, 773-781.

http://dx.doi.org/10.1016/j.applthermaleng.2017.01.089

Zhou, W., Li, Y., Chen, Z., Deng, L. and Gan, Y., 2019, “A Novel Ultrathin Flattened Heat Pipe with Biporous Spiral Woven Mesh Wick for Cooling Electronic Devices,” Energy Conversion and Management, 180, 769-783.

https://doi.org/10.1016/j.enconman.2018.11.031 